\title{
Quality of Life After Tailored Combined Surgery for Stage I Non-Small-Cell Lung Cancer and Severe Emphysema
}

\author{
Eugenio Pompeo, MD, Enrico De Dominicis, MD, Vincenzo Ambrogi, MD, \\ Davide Mineo, MD, Stefano Elia, MD, and Tommaso C. Mineo, MD \\ Division of Thoracic Surgery, Policlinico Tor Vergata University, Rome, Italy
}

Background. We analyzed the early and long-term quality of life changes occurring in 16 patients undergoing tailored combined surgery for stage I non-small-cell lung cancer (NSCLC) and severe emphysema.

Methods. Mean age was $65 \pm 5$ years. All patients had severe emphysema with severely impaired respiratory function and quality of life. Tumor resection was performed with sole lung volume reduction (LVR) in 5 patients, separate wedge resection in 3 patients, segmentectomy in 2 patients, and lobectomy in 6 patients. A bilateral LVR was performed in 5 patients. Quality of life was assessed at baseline and every 6 months postoperatively by the Short-form 36 (SF-36) item questionnaire.

Results. Mean follow-up was $44 \pm 21$ months. All tumors were pathologic stage I. There was no hospital mortality nor major morbidity. Significant improvements

$\mathrm{L}$ ung cancer is the most commonly occurring cancer and the most common cancer-related cause of death among men and women [1]. Patients with chronic obstructive lung disease, including emphysema, have a four- to sixfold increased risk of lung cancer, which becomes even greater when the forced expiratory volume in one second $\left(\mathrm{FEV}_{1}\right)$ falls below $40 \%$ [2]. Among treatment methods currently available, radical resection assures the best chance for cure, while alternative treatment strategies including radiation therapy with or without chemotherapy, have yielded comparatively poor results. Unfortunately, up to $20 \%$ of patients with early stage, resectable non-small-cell lung cancer (NSCLC) are denied surgery due to an impaired respiratory function [1].

Recently, lung volume reduction (LVR) has improved respiratory function and health-related quality of life (HRQOL) for up to 5 years in selected patients with end-stage emphysema [3-7] and has also increased the resection rate of lung cancer [8-10]. Health-related quality of life is one of the primary outcome measures in evaluating LVR and is now recognized as an important measure also in patients with lung cancer [11-13].

Accepted for publication June 13, 2003.

Address reprint requests to Dr Pompeo, Cattedra di Chirurgia, Toracica, Università Tor Vergata, Policlinico Tor Vergata, V.le Oxford, 81, 00133 Rome, Italy; e-mail: pompeo@med.uniroma2.it. occurred for up to 36 months in the general health $(p=$ 0.02) domain and for up to 24 months in physical functioning $(p=0.02)$, role physical $(p=0.005)$, and general health $(p=0.01)$ SF-36 domains. Associated improvements regarded dyspnea index $(-1.3 \pm 0.6)$ forced expiratory volume in one second $(+0.28 \pm 0.2 \mathrm{~L})$, residual volume $(-1.18 \pm 0.5 \mathrm{~L})$ and 6-minute-walking test distance $(+86 \pm 67 \mathrm{~m})$. Actuarial 5-year survival was similar to that of patients with no cancer undergoing LVRS during the same period ( $68 \%$ vs $82 \%, p=$ not significant).

Conclusions. Our study suggests that selected patients with stage I NSCLC and severe emphysema may significantly benefit from tailored combined surgery in terms of long-term quality of life and survival.

(Ann Thorac Surg 2003;76:1821-7)

(C) 2003 by The Society of Thoracic Surgeons

Thus we believe that length of survival, which is usually taken as the ultimate outcome measure of either lung cancer or emphysema treatment, should be routinely integrated with HRQOL assessment. In fact, several years of oxygen-dependent bed-to-chair existence because of respiratory disability evoke quite a desperate perspective while a few years of active comfortable life is invaluable.

Initial reports have suggested that significant clinical improvements can occur after LVR combined with NSCLC resection [11-13] while no study has yet investigated the effect of combined surgery on HRQOL.

Our aim is to analyze early and long-term HRQOL changes in a consecutive series of patients who fulfilled inclusion criteria for LVR and underwent combined resection of stage I NSCLC and emphysema.

\section{Material and Methods}

Between October 1995 and December 2002, out of 148 lung volume reductions performed at our institution, 16 patients had a combined resection of emphysema and NSCLC. Of these, 11 were referred for the suspicion of lung cancer, while in 5 patients the tumor was incidentally discovered during preoperative workup for LVR. In all instances, a rigorous preoperative assessment was carried out including digital chest roentgenogram, total 
body spiral computed tomography (CT), postbronchodilator spirometry, plethysmography, and arterial blood gas analysis. Radiologic morphology of emphysema including severity, heterogeneity, and asymmetric ratio of disease was assessed according to a previously validated visual scoring system [14]. In each patient, heterogeneity was classified as high if a marked difference in distribution of emphysema was detected between the upper half and lower half of the lung; it was classified as low in patients with a homogeneous pattern of distribution. Fiber optic bronchoscopy examination of the airway was always performed preoperatively to confirm resectability and provide material for cytology, cultures, and antibiogram. Mediastinoscopy was never performed since no patient had enlarged hilar or mediastinal lymph nodes at preoperative CT study. Eligibility criteria for combined resection were similar to those applied for a noncancer candidate to LVR. Additional selection criteria included CT evidence of peripheral tumors amenable of wedge resection or central tumors within a severely emphysematous lung lobe deemed resectable by segmentectomy or lobectomy.

Whenever both severely emphysematous areas and a peripheral tumor ( $\leq 3 \mathrm{~cm}$ in maximal size) were localized in the same lobe, tumor resection was accomplished by a typical LVR entailing nonanatomical resection of at least $40 \%$ of the involved lobe. Peripheral tumors, $\leq 3 \mathrm{~cm}$ in maximal size far from the most emphysematous areas, were resected by an additional wedge resection. Larger or more centrally located tumors required segmentectomy or lobectomy with or without tangential resection of the pulmonary artery. Lung volume reductions, wedge resections, and segmentectomies were carried out by means of video-assisted thoracoscopic surgery (VATS), as previously described [15]. Lobectomies were carried out by muscle sparing lateral thoracotomy following insertion of an epidural catheter to optimize perioperative anesthesia and postoperative analgesia. A radical lymphadenectomy was routinely performed in all patients undergoing anatomical resection independently by the type of surgical approach.

The unilateral or bilateral approach was decided on the basis of emphysema morphology. Patients with asymmetric emphysema, and the tumor localized in the more emphysematous lung, underwent intentional unilateral operation. Patients with symmetric disease not requiring lobectomy underwent bilateral $L V R \pm$ additional resection. Lobectomy was never associated with contralateral LVR.

Postoperatively, complete functional and oncological assessment were carried out in all patients including spirometry, total body CT scan, and positron emission tomographic scan.

\section{Outcome Measures}

The Medical Outcome Study Short-Form 36-item Health Survey (SF-36) is an established generic HRQOL instrument [16], which has been validated in Italy [17]. It consists of 36 multiple-choice questions that cover 8 health concepts: physical functioning (PF), social func- tioning (SF), role physical (RP), role emotional (RE), vitality (VT), bodily pain (BP), mental health $(\mathrm{MH})$, and general health $(\mathrm{GH})$ perception with higher scores reflecting a better quality of life. To test the baseline impairment in SF-36 measures, the results of the study group were compared with those of 16 healthy subjects.

Since the SF-36 is a generic measure of health, and not specific for patients with impaired respiratory function, we included as integrated clinical outcome measures also $\mathrm{FEV}_{1}$ for airway obstruction; residual volume (RV) for lung hyperinflation; six-minute walking test (WT) for exercise capacity; and modified Medical Research Council dyspnea index score for the degree of subjective dyspnea. In addition, a self-assessment analysis of postoperative thoracic pain was added using a four-item questionnaire $(0=$ no pain; $1=$ pain when weather changes; $2=$ pain once a week; $3=$ pain every day). Finally, survival was analyzed and compared with that of 132 patients with no cancer undergoing LVR for emphysema during the same period.

\section{Statistical Analysis}

Group descriptive statistics are presented as means \pm standard deviation (SD) and(or) standard error of the mean (SEM) . Paired and unpaired data were compared using the nonparametric Wilcoxon and Mann-Whitney tests, respectively. Internal consistency of the questionnaire was evaluated by the Alpha Cronbach's test (highest value $=1$, lowest $=0$ ). Survival was analyzed by the Kaplan-Meier method, and differences between curves were assessed by the Log Rank test. Results were considered significant for $p$ less than 0.05

\section{Results}

Mean age was $65 \pm 5$ years. All patients fulfilled standard inclusion criteria for LVR. In particular, all patients had emphysema graded as severe and diffuse with disabling symptoms despite maximized medical therapy, while no patient had isolated giant bullous emphysema.

Among 9 patients who were on long-term oxygen therapy, 6 had only nocturnal oxygen therapy and 3 had continuous oxygen therapy. Internal consistency of the SF-36 questionnaire at baseline and 6 months was satisfactory $(0.80$ to 0.78$)$ as well as the rate of answered questions $(88 \%)$. When compared with a group of healthy people, patients with NSCLC and emphysema had a significantly more compromised status in all baseline SF-36 HRQOL domains but BP (Table1).

At the operation, tumor resection was accomplished by sole LVR in 5 instances ( 3 bilateral and 2 unilateral); separate wedge in 3 instances ( 1 sole, 1 plus unilateral LVR, and 1 plus bilateral LVR); segmentectomy in 2 instances ( 1 sole 1 plus unilateral LVR); and sole lobectomy in 6 instances ( 2 right upper lobectomies, 1 left lower lobectomy, and 3 left upper lobectomies). In 2 patients undergoing left upper lobectomy, a tangential resection of the pulmonary artery encompassing the origin of the anterior segmental branch in one patient and anterior plus superior segmental branches in an- 
Table 1. Baseline Scores in SF-36 HRQOL Domains in the Study Group Compared with a Healthy Control Group

\begin{tabular}{lccc}
\hline Domain & $\begin{array}{c}\text { Study Group } \\
(\mathrm{n}=16) \\
\text { Score }\end{array}$ & $\begin{array}{c}\text { Control Group } \\
(\mathrm{n}=16) \\
\text { Score }\end{array}$ & P Value \\
\hline PF & $39 \pm 19$ & $95 \pm 7$ & $<0.0001$ \\
RP & $27 \pm 21$ & $77 \pm 42$ & 0.005 \\
BP & $89 \pm 15$ & $99 \pm 3$ & 0.1 \\
GH & $37 \pm 16$ & $71 \pm 22$ & 0.0004 \\
VT & $47 \pm 21$ & $95 \pm 5$ & $<0.0001$ \\
SF & $54 \pm 28$ & $91 \pm 10$ & 0.002 \\
RE & $50 \pm 37$ & $83 \pm 36$ & 0.02 \\
MH & $48 \pm 22$ & $91 \pm 6$ & $<0.0001$ \\
\hline
\end{tabular}

$\mathrm{PF}=$ physical functioning; $\mathrm{RP}=$ role physical $; \quad \mathrm{BP}=$ bodily pain; $\quad \mathrm{GH}=$ general health; $\quad \mathrm{VT}=$ vitality; $\quad \mathrm{SF}=$ social functioning; $\quad \mathrm{RE}=$ role emotional; $\quad \mathrm{MH}=$ mental health.

other, were carried out and the defect was closed with a polytetrafluoroethylene patch. There was no hospital mortality. Eight nonfatal complications including 6 prolonged air leaks and 2 transient cardiac arrhythmias occurred in 7 patients $(44 \%)$. Hospital stay averaged 11.5 \pm 5 days (range, 6 to 18 days).

The average size of the resected tumors was $2.4 \mathrm{~cm}$ (range, 1.1 to $6.0 \mathrm{~cm}$ ). Pathologic staging showed 11 T1N0M0 and 5 T2N0M0 tumors. Between the 2 patients undergoing lobectomy with tangential resection of the pulmonary artery, both lesions were classified as T2. Histology revealed 9 adenocarcinomas, 5 squamous cell carcinomas, and 2 large cell carcinomas. Three tumors were classified as scar carcinomas. No patient underwent adjuvant therapy.

Follow-up averaged $44 \pm 21$ months. Sixteen patients were available at 6 months, 15 at 12 months, 13 at 24 months, and 9 at 36 months. Significant changes in SF-36 HRQOL domains at six months regarded PF $(+22 \pm 16, p$ $=0.0001), \mathrm{RP}(+22 \pm 18, p=0.0006), \mathrm{GH}(+15 \pm 14, p=$ $0.0001), \mathrm{VT}(+8 \pm 7, p=0.0006), \mathrm{SF}(+15 \pm 19, p=0.0009)$, $\mathrm{RE}(+15 \pm 24, p=0.01)$, and $\mathrm{MH}(+3 \pm 6, p=0.01)$. These improvements remained significant for up to 36 months

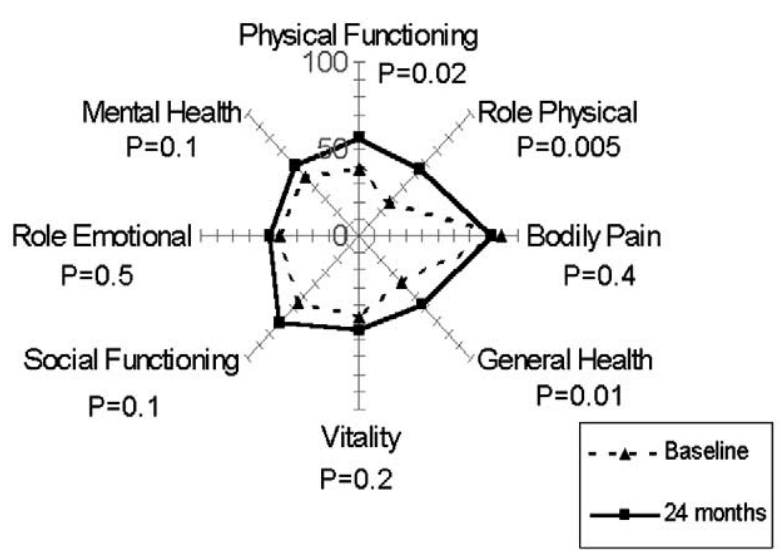

Fig 1. Polar graph showing 24-month changes in SF-36 health domains scores in the study group $(N=13)$.

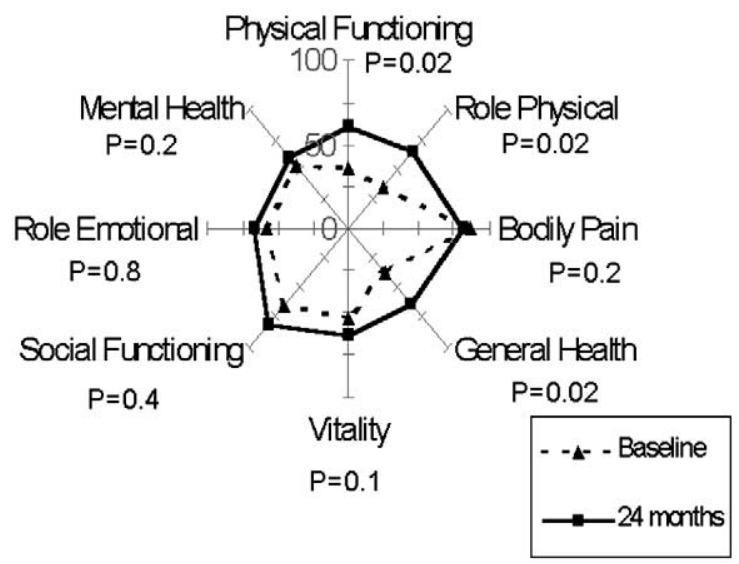

Fig 2. Polar graph showing 24-month changes in SF-36 health domains scores in patients undergoing nonanatomical resections $(N=$ 7).

for GH only, for up to 24 months for PF and RP (Figs 1 to 3 ), and for up to 12 months for RE and VT.

Acute clinical improvements at 6 months regarded dyspnea index, FEV1, RV, WT, $\mathrm{PaO}_{2}$, and $\mathrm{PaCO}_{2}$. At 24 months, FEV1, RV, WT, and dyspnea index were still significantly improved, while at 36 months dyspnea index only remained significantly improved (Table 2 ).

At univariate analysis, neither the type of surgical approach (unilateral vs bilateral) nor the type of resection (nonanatomical versus anatomical resection) affected the clinical outcome measure results; differently, a greater improvement in FEV1 and RV was achieved in patients with higher degree of eterogeneity of the emphysema (Table 3). As far as HRQOL domains were concerned, greater improvements in PF and GH occurred in patients undergoing nonanatomical resection while greater improvements in RP and VT occurred in patients with more heterogeneous emphysema (Table 4). Finally, at 6, 12, 24, and 36 months, no difference was found in clinical measures and HRQOL domains changes when compar-

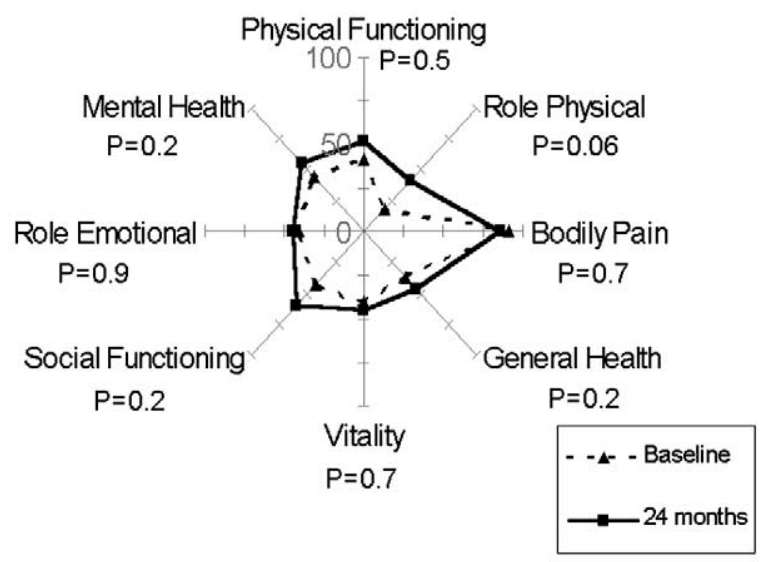

Fig 3. Polar graph showing 24-month changes in SF-36 health domains scores in patients undergoing anatomical resections $(N=6)$. 
Table 2. Baseline Clinical Measures and Postoperative Results

\begin{tabular}{|c|c|c|c|c|c|}
\hline Variable & Baseline & $\begin{array}{l}6 \text { Months } \\
(\mathrm{N}=16)\end{array}$ & $\begin{array}{l}12 \text { Months } \\
(\mathrm{N}=16)\end{array}$ & $\begin{array}{l}24 \text { Months } \\
(\mathrm{N}=13)\end{array}$ & $\begin{array}{c}36 \text { Months } \\
(\mathrm{N}=10)\end{array}$ \\
\hline DI (score) & $3.2 \pm 0.6$ & $1.9 \pm 0.7^{*}$ & $1.8 \pm 0.9^{*}$ & $2.1 \pm 0.6^{*}$ & $2.2 \pm 0.8^{\circ}$ \\
\hline $\mathrm{FEV}_{1}(\mathrm{~L})$ & $0.92 \pm 0.5$ & $1.20 \pm 0.4^{*}$ & $1.20 \pm 0.4^{*}$ & $1.06 \pm 0.3^{*}$ & $1.00 \pm 0.4$ \\
\hline FVC (L) & $2.6 \pm 0.7$ & $2.81 \pm 0.6^{*}$ & $2.85 \pm 0.6^{\circ}$ & $2.78 \pm 0.6$ & $2.78 \pm 0.5$ \\
\hline $\mathrm{RV}(\mathrm{L})$ & $5.2 \pm 0.7$ & $3.99 \pm 0.7^{*}$ & $4.13 \pm 0.9^{*}$ & $4.20 \pm 0.8^{*}$ & $4.50 \pm 1.0^{\circ}$ \\
\hline TLC (L) & $8.3 \pm 0.9$ & $7.4 \pm 1.0$ & $7.6 \pm 1.0$ & $7.5 \pm 0.9$ & $7.8 \pm 0.7$ \\
\hline $\mathrm{PaO}_{2}(\mathrm{~mm} \mathrm{Hg})$ & $68 \pm 6$ & $70 \pm 7^{*}$ & $70 \pm 6^{*}$ & $69 \pm 6$ & $66 \pm 8^{\circ}$ \\
\hline $\mathrm{PaCO}_{2}(\mathrm{~mm} \mathrm{Hg})$ & $40 \pm 2$ & $39 \pm 2^{\circ}$ & $39 \pm 2$ & $40 \pm 3$ & $41 \pm 4$ \\
\hline $\operatorname{DCO}(\%)$ & $40 \pm 21$ & $40 \pm 17$ & $43 \pm 17$ & $39 \pm 17$ & $38 \pm 14^{*}$ \\
\hline WT (m) & $355 \pm 144$ & $441 \pm 87^{*}$ & $465 \pm 88^{*}$ & $452 \pm 62^{*}$ & $416 \pm 87$ \\
\hline Oxygen use (patients) & 9 & 3 & 4 & 5 & 4 \\
\hline Steroid use (patients) & 16 & $4^{*}$ & $6^{*}$ & $7^{*}$ & 7 \\
\hline
\end{tabular}

Preoperative versus postoperative result: ${ }^{*} \mathrm{P}<0.02 ;{ }^{\circ} \mathrm{P}<0.05$.

$\mathrm{DI}=$ modified medical research council dyspnea index; $\quad \mathrm{FEV}_{1}=$ forced expiratory volume in one second; $\quad \mathrm{FVC}=$ forced vital capacity; $\quad \mathrm{RV}=$ residual volume; $\quad \mathrm{PaO}_{2}=$ arterial oxygen tension; $\quad \mathrm{PaCO}_{2}=$ arterial carbon dioxide tension; DCO = diffusing capacity for carbon monoxide; $\quad$ WT $=$ six-minute walking test.

ing the results achieved by the 6 patients undergoing lobectomy with those of the remaining 10 patients.

Analysis of chronic pain score showed, on average, a peak at 6 months and a subsequent decrease (Fig 4). In particular, at $6,12,24$, and 36 months there were 11, 6, 3, and 2 patients, respectively, who suffered some thoracic pain. This result was associated with a paradoxical change in BP, which was the only domain that slightly deteriorated postoperatively (Figs 1-3).

So far, no patient has died due to respiratory failure while 2 patients died due to recurrence; one after an anatomical resection and one after a nonanatomical resection. Recurrence was local in one patient and distant (brain metastases) in one other. Two patients who developed mediastinal and bone metastases, respectively, are alive with recurrence. Comparison of long-term survival curve with that of patients undergoing LVR for sole emphysema during the same period showed no difference among the groups (Fig 5).

\section{Comment}

The World Health Organization defines HRQOL as an individual perception of their position in life in the context of the cultural and value system in which they live, and in relation to their goals, expectations, standards, and concerns. Yet, measuring HRQOL has been addressed to a multidimensional subjective assessment of feelings and wellness and satisfaction, as well as perceptions of impairments and problems [18].

Patients with severe emphysema experience negative changes in mood and social behavior that are related to a variety of physiological and psychological factors. Chronic hypoxemia and dyspnea, poor activity tolerance, several types of drugs used in treatment, and frequent hospitalization may all produce detrimental changes in both social and emotional aspects of HRQOL [16].

Several different methods have been developed to assess HRQOL including the SF-36 [14], Sickness Impact Profile [19], Nottingham Health Profile [20], St. George's Chronic Respiratory Disease Questionnaire [21], and the European Organization For Research and Treatment of Cancer quality of life questionnaire [13].

The SF-36 has been widely used as a general health status instrument [16]. In addition, it has also been employed to assess changes in HRQOL after LVR [4, 5, 20]. Cooper and colleagues [20] and Moy and colleagues [4] reported significant improvements in SF-36 HRQOL

Table 3. Effect of Surgical Approach, Type of Resection and Degree of Heterogeneity of the Emphysema on Pre- Versus 6Monthly Postoperative Changes in Clinical Outcome Measures

\begin{tabular}{|c|c|c|c|c|c|c|}
\hline \multirow{2}{*}{$\begin{array}{l}\text { Clinical } \\
\text { Outcome } \\
\text { Measure }\end{array}$} & \multicolumn{2}{|c|}{$\begin{array}{c}\text { Type of Approach } \\
\text { (Unilateral Versus Bilateral) }\end{array}$} & \multicolumn{2}{|c|}{$\begin{array}{c}\text { Type of Resection } \\
\text { (Nonanatomical Versus } \\
\text { Anatomical) }\end{array}$} & \multicolumn{2}{|c|}{$\begin{array}{l}\text { Heterogeneity of Emphysema } \\
\text { (Low Versus High) }\end{array}$} \\
\hline & $\mathrm{N}=11$ & $\mathrm{~N}=5$ & $\mathrm{~N}=8$ & $\mathrm{~N}=8$ & $\mathrm{~N}=8$ & $\mathrm{~N}=8$ \\
\hline$\Delta \mathrm{FEV}_{1}(\mathrm{~L})$ & $0.26 \pm 0.2$ & $0.32 \pm 0.2$ & $0.33 \pm 0.2$ & $0.23 \pm 0.2$ & $0.12 \pm 0.1$ & $0.44 \pm 0.1^{\S}$ \\
\hline$\Delta \mathrm{RV}(\mathrm{L})$ & $1.1 \pm 0.4$ & $1.4 \pm 0.5$ & $1.3 \pm 0.6$ & $1.1 \pm 0.3$ & $1.2 \pm 0.5$ & $1.2 \pm 0.4$ \\
\hline$\Delta W T(\mathrm{~m})$ & $88 \pm 58$ & $82 \pm 48$ & $103 \pm 64$ & $69 \pm 37$ & $82 \pm 69$ & $89 \pm 38$ \\
\hline$\Delta \mathrm{DI}$ (score) & $1.2 \pm 0.6$ & $1.6 \pm 0.5$ & $1.4 \pm 0.5$ & $1.2 \pm 0.7$ & $1.0 \pm 0.5$ & $1.6 \pm 0.5^{*}$ \\
\hline
\end{tabular}

Intergroup difference, ${ }^{*} \mathrm{P}=0.06 ;{ }^{\circ} \mathrm{P}<0.04 ;{ }^{\S} \mathrm{P}<0.001$.

$\mathrm{DI}=$ modified medical research council dyspnea index; $\quad \mathrm{FEV}_{1}=$ forced expiratory volume in one second; $\quad \mathrm{RV}=$ residual volume; $\quad \mathrm{WT}=$ six-minute walking test. 
Table 4. Effect of Surgical Approach, Type of Resection and Degree of Heterogeneity of the Emphysema on Pre- Versus 6Monthly Postoperative Changes in HRQOL Measures

\begin{tabular}{|c|c|c|c|c|c|c|}
\hline \multirow{2}{*}{$\begin{array}{l}\text { SF-36 QOL } \\
\text { Domain }\end{array}$} & \multicolumn{2}{|c|}{$\begin{array}{c}\text { Type of approach } \\
\text { (Unilateral Versus Bilateral) }\end{array}$} & \multicolumn{2}{|c|}{$\begin{array}{c}\text { Type of Resection } \\
\text { (Nonanatomical Versus Anatomical) }\end{array}$} & \multicolumn{2}{|c|}{$\begin{array}{l}\text { Heterogeneity of } \\
\text { Emphysema } \\
\text { (Low Versus High) }\end{array}$} \\
\hline & $\mathrm{N}=11$ & $\mathrm{~N}=5$ & $\mathrm{~N}=8$ & $\mathrm{~N}=8$ & $\mathrm{~N}=8$ & $\mathrm{~N}=8$ \\
\hline$\Delta \mathrm{PF}$ & $21 \pm 14$ & $24 \pm 22$ & $31 \pm 14^{\circ}$ & $14 \pm 13$ & $19 \pm 16$ & $26 \pm 16$ \\
\hline$\Delta \mathrm{RP}$ & $18 \pm 16$ & $30 \pm 21$ & $28 \pm 16$ & $16 \pm 19$ & $12 \pm 13$ & $31 \pm 18^{*}$ \\
\hline$\Delta \mathrm{BP}$ & $-26 \pm 27$ & $-29 \pm 28$ & $-29 \pm 25$ & $-25 \pm 29$ & $-23 \pm 31$ & $-31 \pm 22$ \\
\hline$\Delta \mathrm{GH}$ & $14 \pm 10$ & $18 \pm 22$ & $22 \pm 15^{\circ}$ & $8.0 \pm 8.0$ & $13 \pm 10$ & $17 \pm 17$ \\
\hline$\Delta \mathrm{VT}$ & $8.0 \pm 7.0$ & $7.0 \pm 8.0$ & $8.0 \pm 7.0$ & $7.0 \pm 8.0$ & $3.0 \pm 5.0$ & $12 \pm 7.0^{\circ}$ \\
\hline$\Delta \mathrm{SF}$ & $15 \pm 16$ & $15 \pm 27$ & $17 \pm 21$ & $13 \pm 17$ & $10 \pm 13$ & $20 \pm 23$ \\
\hline$\Delta \mathrm{RE}$ & $18 \pm 27$ & $7.0 \pm 15$ & $17 \pm 25$ & $12 \pm 25$ & $12 \pm 25$ & $17 \pm 25$ \\
\hline$\Delta \mathrm{MH}$ & $4.0 \pm 6.0$ & $0.0 \pm 8.0$ & $2.0 \pm 3.0$ & $4.0 \pm 8.0$ & $1.0 \pm 6.0$ & $5.0 \pm 6$ \\
\hline
\end{tabular}

Intergroup difference, ${ }^{*} \mathrm{P}=0.06 ;{ }^{\circ} \mathrm{P}<0.04 ;{ }^{\S} \mathrm{P}<0.001$.

$\mathrm{PF}=$ physical functioning; $\quad \mathrm{RP}=$ role physical $; \quad \mathrm{BP}=$ bodily pain; = role emotional; $\mathrm{MH}=$ mental health.

domains. Yet, Hamacher and colleagues [5] reported that improvements in PF, RP, VT, SF, and MH SF-36 domains occurred early after thoracoscopic LVR and lasted for up to 24 months. More recently, Yusen and colleagues [7] reported that a significant clinical change in PF, which has probably the most relevance for patients with emphysema, occurred at 6 months, 3 years, and 5 years, in $90 \%, 69 \%$, and $57 \%$ of the patients, respectively. Finally, Goldstein and colleagues [6] reported that LVR resulted in important benefits in disease-specific quality of life compared with medical management, which remained sustained at 12 months after treatment. Yet, in the same series, no difference between patients treated bilaterally or unilaterally was found for any of the outcome measures at baseline and following surgery.

As far as the effects of lung cancer in HRQOL are concerned, they tend to deteriorate significantly with increasing extent of disease [22] and are mainly ad-

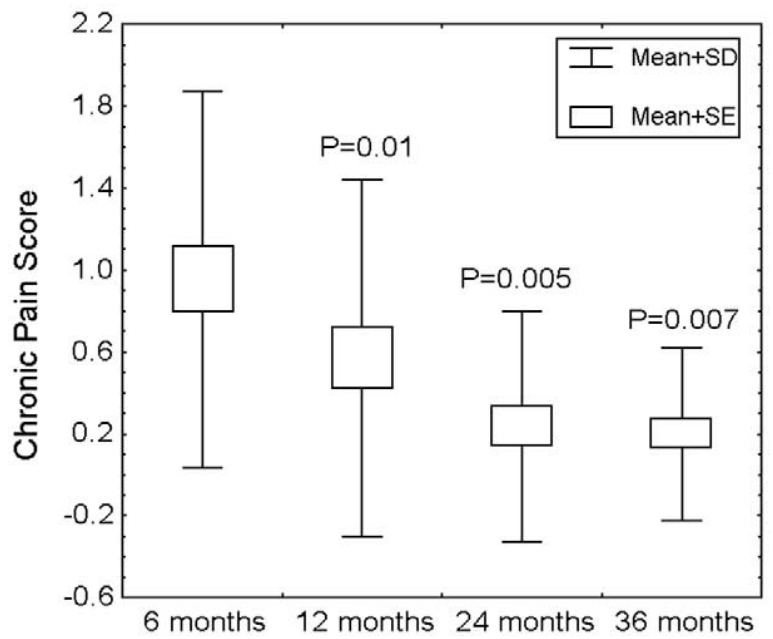

Fig 4. Chronic pain scores at $6,12,24$, and 36 months; $\mathrm{p}$ values refer to comparisons with the 6-month result.
$\mathrm{GH}=$ general health $; \quad \mathrm{VT}=$ vitality $; \quad \mathrm{SF}=$ social functioning; $\quad \mathrm{RE}$

dressed to cancer symptoms such as chronic pain, weakness, and tiredness. These symptoms are usually associated with recurrent disease, which is thus the most important determinant of postoperative HRQOL. Dales and colleagues [12] reported that HRQOL deteriorated early after thoracotomy and returned to preoperative status since 6 months postoperatively. Zieren and colleagues [11] also reported that the postoperative deterioration of HRQOL was mainly affected by restrictions related to physical activities, job and household tasks, and disease symptoms, while limitations in emotional and social domains were less frequent and less severe. In addition, Nou and Aberg [23] reported that HRQOL was better in 5-year surviving patients and poorer in those receiving nonresectional thoracotomy.

We assumed that in this series, the main factors influencing HRQOL were the degree of functional disability, the degree of postoperative improvements, and the occurrence of thoracic pain due to the early cancer stage

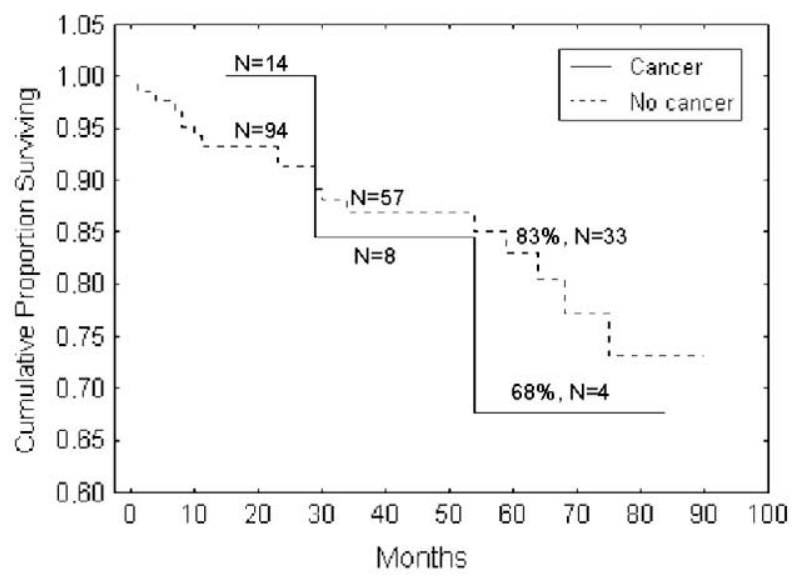

Fig 5. Cumulative survival curve compared with that of 132 patients with sole emphysema undergoing lung volume reduction during the study period. 
and the absence of preoperative cancer-related symptoms. Nonetheless, the presence of lung cancer can affect HRQOL by influencing the surgical strategy, which must be guided not only by the distribution of the emphysematous target areas but also by the tumor characteristics and localization.

The main finding of our study is that rigorously selected patients with end-stage emphysema and stage I NSCLC can significantly benefit from tailored combined surgery in terms of both HRQOL domains changes and long-term survival. As a matter of fact, significant improvements occurred early after surgery in several SF-36 HRQOL domains and remained sustained for up to 36 months. These were accompanied by significant improvements in respiratory function measures, exercise capacity, and subjective dyspnea. A significantly better result was achieved in PF and GH domains in patients undergoing nonanatomical resections compared with those undergoing anatomical resections, while improvements in RP and VT domains were greater in patients with more heterogeneous emphysema. Yet, patients with a high degree of heterogeneity had a greater improvement in $\mathrm{FEV}_{1}$, confirming that heterogeneous distribution of disease is one of the main prerequisites predicting maximal benefit in LVR [20]. In addition, comparison of unilaterally versus bilaterally treated patients showed no difference in postoperative HRQOL domains and clinical improvements. Though the small cohort clearly limits definitive inferences, our results corroborate the previous finding that in patients with asymmetric emphysema, benefit of unilateral LVR can compare to that of the bilateral treatment. In addition, our results confirm that postoperative thoracic pain is not a negligible problem in patients undergoing thoracic surgery by either VATS or thoracotomy and can negatively affect HRQOL [24].

Among 8 patients who have undergone anatomical resections, 6 underwent lobectomy and, in 2 of these, a tangential resection of the pulmonary artery was performed to avoid a pneumonectomy. Satisfactory improvements in respiratory function measures, exercise capacity, and subjective dyspnea had already been reported after lobectomy for NSCLC in emphysema patients by De Meester and colleagues [9] and by Edwards and colleagues [10] while no data existed so far on HRQOL changes. In a recent series on LVR [7], lobectomies were carried out in patients with a severely emphysematous target lobe but contralateral LVR was always added. Although we acknowledge that bilateral treatment is the standard of care in patients undergoing LVR, several reasons led us to prefer sole lobectomy. In fact, even in those patients in whom emphysema is prevailing in one lobe, some preserved tissue is almost always present and is sacrificed if lobectomy is performed. Thus, in patients undergoing lobectomy, we preferred to avoid contralateral LVR to limit the risk of resection of a further amount of preserved lung tissue, which could eventually lead to pulmonary hypertension and cor pulmonale. Moreover, with unilateral operation overall operative time is significantly shorter than that required for a bilateral procedure including lobectomy. Finally, our recent finding that a staged bilateral LVR can result in more prolonged benefit than one-stage bilateral treatment can suggest to delay contralateral LVR until the benefit achieved with unilateral procedure is lost [25].

In fact, meaningful improvements in $\mathrm{FEV}_{1}, \mathrm{RV}, \mathrm{WT}$, dyspnea index, and HRQOL SF-36 domains occurred also in patients treated by lobectomy and more complex tissue sparing resections, demonstrating that they can be safely carried out in severely emphysematous patients provided that the tumor is contained in an emphysematous lobe.

It is thus conceivable that lobectomy behaved as a lobar LVR, which exerted a bilateral effect on chest wall mechanics possibly due to the interdependence between the hemithoraces, the compliance of the lungs, and the mobility of the mediastinum.

The $68 \% 5$-year survival rate in this series is highly satisfactory if one considers that the expected 5-year survival in unselected patients undergoing lobectomy for stage I NSCLC ranged between $67 \%$ for stage IA and $57 \%$ for stage IB [26], whereas 3-year survival of patients undergoing LVR for emphysema is between $65 \%$ and $80 \%[27,28]$.

Hypothetical reasons to explain such a satisfactory outcome include, first, the strict radiologic surveillance of patients with emphysema that can help discover early stage asymptomatic tumors. Second, the reduced vascular and lymphatic peritumoral network often found in severely emphysematous lungs could limit the probability of an early tumor spread. This hypothesis is supported not only by our overall survival rate but also by the finding that no positive lymph nodes were found among eight patients undergoing radical lymphadenectomy. This is in contrast with the common finding that nodal occult metastases can be detected in up to $20.4 \%$ of the patients with peripheral tumors of $2.0 \mathrm{~cm}$ or less in diameter [29]. For these reasons, although lobectomy still remains our preferred type of resection for stage I [30] NSCLC, wide wedge resections as well revealed an acceptable oncologic treatment for these particular patients.

We conclude that by a rigorous preoperative evaluation and a tailored surgical strategy including nonanatomical, anatomical, and more complex tissue sparing resections based on emphysema morphology and the tumor characteristics, significant improvements in HRQOL domains and highly satisfactory long-term survival can be achieved in patients with stage I NSCLC and severe emphysema.

This study was supported partially by the Ministero dell'Universitá e della Ricerca (MIVR) (Grant COFIN \#9906274194-06 and 2001061131-001); by the Cousiglio Nazionale delle Richerche (Single Project 2002 CNR CU0100935CT26), and by the Progetto Ministero dells Salute-Regione Lazio 2002.

\section{References}

1. Mentzer SJ, Swanson SJ. Treatment of patients with lung cancer and severe emphysema. Chest 1999;116(S6):477-9. 
2. Kishi K, Gurney JW, Shroeder DR, Scanlon PD, Swensen SJ, Jett JR. The correlation of emphysema or airway obstruction with the risk of lung cancer: a matched case-controlled study. Eur Respir J 2002;19:1093-8.

3. Leyenson V, Furukawa S, Kuzma AM, Cordova F, Travaline J, Criner JG. Correlation of changes in quality of life after lung volume reduction surgery with changes in lung function, exercise, and gas exchange. Chest 2000;118:728-35.

4. Moy ML, Ingenito EP, Mentzer SJ, Evans RB, Reilly JJ. Health-related quality of life improves following pulmonary rehabilitation and lung volume reduction surgery. Chest 1999;115:383-9.

5. Hamacher J, Büchi S, Georgescu CL, et al. Improved quality of life after lung volume reduction surgery. Eur Respir J 2002;19:54-60.

6. Goldstein RS, Todd TRJ, Guyatt G. Influence of lung volume reduction surgery (LVRS) on health related quality of life in patients with chronic obstructive pulmonary disease. Thorax 2003;58:405-10.

7. Yusen RD, Lefrak SS, Gierada DS, et al. A prospective evaluation of lung volume reduction surgery in 200 consecutive patients. Chest 2003;123:1026-37.

8. McKenna RJ, Fischel RJ, Brenner M, Gelb AF. Combined operations for lung volume reduction surgery and lung cancer. Chest 1996;110:885-8.

9. DeMeester SR, Patterson GA, Cooper JD. Lobectomy combined with volume reduction for patients with lung cancer and advanced emphysema. J Thorac Cardiovasc Surg 1998; 115:681-8.

10. Edwards JG, Duthie DJR, Waller DA. Lobar volume reduction surgery: a method of increasing the lung cancer resection rate in patients with emphysema. Thorax 2001;56:791-5.

11. Zieren HU, Müller JM, Hamberger U, Pichlmaier H. Quality of life after surgical therapy of bronchogenic carcinoma. Eur J Cardiothorac Surg 1996;10:233-7.

12. Dales RE, Belanger R, Shanji FM, Leech J, Crepeau A, Sachs HJ. Quality-of-life following thoracotomy for lung cancer. J Clin Epidemiol 1994;47:1443-9.

13. Li WW, Lee TW, Ng CS, Sihoe AD, Wan IY, Yim AP. Quality of life following lung cancer resection: video-assisted thoracic surgery vs thoracotomy. Chest 2002;122:584-9.

14. Pompeo E, Sergiacomi G, Nofroni I, Roscetti W, Simonetti G, Mineo TC. Morphologic grading of emphysema is useful in the selection of candidates for unilateral or bilateral reduction pneumoplasty. Eur J Cardiothorac Surg 2000;17:680-6.

15. Ambrogi V, Pompeo E, Matteucci G, Mineo TC. Combined surgery for emphysema and lung cancer. Eur J Cardiothorac Surg 2000;18:372-4.
16. Mahler D, Mackowiak JI. Evaluation of the Short-Form 36-item questionnaire to measure health-related quality of life in patients with COPD. Chest 1995;107:1585-9.

17. Apolone G, Mosconi P. The Italian SF-36 Health Survey: translation, validation and norming. J Clin Epidemiol 1998; 51:1025-36.

18. World Health Organization. The World Health Organization Quality of Life Assessment (WHOQOL): position paper from the World Health Organization. Soc Sci Med 1995;41:1403-9.

19. O'Brien GM, Furukawa S, Kuzma AM, Cordova F, Criner GJ. Improvements in lung function, exercise, and quality of life in hypercapnic COPD patients after lung volume reduction surgery. Chest 1999;115:75-84.

20. Cooper JD, Trulock EP, Triantafillou AN, et al. Bilateral pneumectomy (volume reduction) for chronic obstructive pulmonary disease. J Thorac Cardiovasc Surg 1995;109:10619.

21. Norman M, Hillerdal G, Orre L, et al. Improved lung function and quality of life following increased elastic recoil after lung volume reduction surgery in emphysema. Respir Med 1998;92:653-8.

22. Ruckdeschel JC, Piantadosi S, and and the Lung Cancer Study Group. Quality-of-life assessment in lung cancer surgery for broncogenic carcinoma. Theor Surg 1991;6:201-5.

23. Nou E, Aberg T. Quality of survival in patients with surgically treated bronchial carcinoma. Thorax 1980;35:255-63.

24. Landreneau RJ, Mack MJ, Hazelrigg SR, et al. Prevalence of chronic pain after pulmonary resection by thoracotomy or video-assisted thoracic surgery. J Thorac Cardiovasc Surg 1994;107:1079-86.

25. Pompeo E, Mineo TC. Long term outcome of staged versus one-stage bilateral thoracoscopic reduction pneumoplasty. Eur J Cardiothorac Surg 2002;21:627-33.

26. Mountain CF. Revisions in the international system for staging lung cancer. Chest 1997;111:1710-7.

27. Brenner M, McKenna RJ, Chen JC, et al. Survival following bilateral staple lung volume reduction surgery for emphysema. Chest 1999;115:390-6.

28. Serna DL, Brenner M, Osann KE, et al. Survival after unilateral versus bilateral lung volume reduction surgery for emphysema. J Thorac Cardiovasc Surg 1999;118:1101-9.

29. Wu J, Ohta Y, Minato H, et al. Nodal occult metastasis in patients with peripheral lung adenocarcinoma of $2.0 \mathrm{~cm}$ or less in diameter. Ann Thorac Surg 2001;71:1772-8.

30. Ginsberg RJ, Rubinstein L, and for the Lung Cancer Study Group. Randomized trial of lobectomy versus limited resection for patients with T1 N0 non-small cell lung cancer. Ann Thorac Surg 1995;60:615-23. 